\title{
Two Suns? The Algorithmic State: The Bones of the Argument
}

The argument in the last part of the Two Suns? series was summed up as follows. There are several spaces or forms of space involved; territorial space, outer space, cyberspace and living space, And there is data to be found and owned in each of these spaces. That data may be processed using algorithms in each space and across all spaces. The argument has been developed as follows. In Part One, the bones, at least some of them, of the argument in the series may be seen in the title, Two Suns? The State of Amazon? Bezonomics, market control and the algorithmic state. Books by Brian Dumaine and Rob Hart, Bezonomics and The Warehouse respectively, were the jump off points for the discussion along with earlier work by me on incipient states. I asked about Amazon:

Is it an entity that now has a force, a scale, an ethic and a set of borders that speaks of a state-like 
situation wherein people rely and trust Amazon to fulfil their needs?

I was and still am fascinated by multipliers, using that word in its general sense, and asked whether the coronavirus pandemic had acted as a recent multiplier for Amazon but more particularly how Amazon had come to grow. This began a series of investigations. To begin with I looked at instant gratification through delivery and the proximity of Alexa. And I looked at data.

I also asked how Amazon was anchored and whether that anchorage was necessarily in the USA. With those points in mind the argument proceeded:

Now I want to look at Amazon with regard to recent literature taking five or six works into consideration these being Lina Khan's writing on Amazon and antitrust legislation, Steven Berry's work on hubs, Geoffrey West's book Scale as well as the work by Dumaine and Hart mentioned above along with references to a recent book by Ronan Farrow and a consideration of Gaby Wood's Living Dolls.

My reasoning for the use of Dumaine and Hart as critical reference points went as follows:

Dumaine's work is critical. His book Bezonomics is the primer in a study of Amazon charting the rise of Bezos, the use of algorithms and the Amazon flywheel' in a clear and effective manner and 
making several critical insights as far as this presentation is concerned including the reference to antitrust legislation of 1905 .

Hart's book The Warehouse which is not an academic thesis but a futuristic view of Amazon the company not being mentioned by name in the book- is prescient in terms of the multiplier effect that the pandemic has had on Amazon. There are several insights in The Warehouse that might inform this presentation but the vision, what seems to me to be an accurate one, of an America or a world becoming more dependent on Amazon-like hubs is in keeping with its 2019 publication date.

Two other key texts for me were Geoffrey West's Scale and an article by Lina Khan on anti trust law. These two scholars were addressing the right issues but from points of view that I felt wrong or misplaced. At the same time I felt both works to be impressive and important. West put too much emphasis on the city for me and Khan, like the Milan School and their idea of the Algorithmic State, discussed later, put too much emphasis on the strength of law, especially the law of the USA.

I gave some emphasis to the idea of hubs. The hub of the warehouse or fulfilment centre, the hub in the sky and the use of drones and looked ahead to discussion of hubs in near space and the later consideration of shells as well as the conceptual hub in cyberspace, in the cloud. As the article proceeded I referred to Steven Berry's work in this area. 
I also started to mention and discuss the terms and jargon involved such as 'the Amazon Flywheel' and began to consider the work of Morris and others. The terms involved are significant with a great many being discussed across the Two Suns? series. A Big Tech dictionary of terms might not be out of the question.

It was noted:

\begin{abstract}
Again we come, perhaps, to the question as to whether Amazon needs the United States as a base. Why not an island state as a centre for Amazon, why not, say, Nauru, a state where the natural resource might be running out and there is a need for an economic benefactor of some kind?
\end{abstract}

This relates to points raised in the latter parts of the Two Suns? series about Netflix which, of all the Big Tech operators, has the best developed view of an international operation. Regarding the 'shadowing' operation described in No Rules, Rules, the book by Hastings and Meyer on Netflix whereby Cheryl Sandberg of Facebook follows Hastings around Netflix operations it would be surprising if other Big Tech operators are not thinking about the internationalisation of Netflix's operations as a model for development. In Seven the example of Baidu, a Chinese operator now being based in the 
Cayman Islands provides an example of the island state as a base.

It was also asked: Is Amazon an incipient state within the US?

Questions were also asked about leadership and dynasty and these might be be seen as addressed in the last parts of the Two Suns? series especially Six about techno feudalism.

The significance of service to the client was noted in the Amazon case. Later and throughout the Two Suns? series the idea of service to the client and service to the citizen are considered side by side:

...one important point here, going back especially to Dumaine, is the intention to serve in the Amazon culture. This is not leadership by fiat, not leadership by committee or by kin, it is leadership by ascription of power to the client, the intention is to out-serve any competition.

The economic history of Amazon with its apparent disdain for the profit line and the attention to market dominance through service needs to be treated by an economist, Dumaine having done an initial description of some note as has Khan from a legal point of view. The flywheel works essentially by faster, more 
reliable service getting better and providing better value for money, better algorithms, all the time. The way the flywheel works is part of its attraction to the public and why the level of interest as well as trust is high. We might call this an incipient market state except that Amazon offers a comfort zone of immediate service through Alexa and other things considered below as well as a place to buy and sell.

Regarding citizenship, later on article One it was suggested:

The ethic at Amazon, the concentration on the client that Dumaine notes is central to all that Bezos does and is similar, or at least comparable, to the attention given to the citizen in a well functioning state. This attention it might be argued, fulfils a basic need and Bezos has taken this need and amplified it to be visceral, immediate and wish fulfilling.

Earlier though, there was a consideration of Amazon as an Algorithmic State:

A market state? Like the mercantile states of old, like Venice in days of yore or like Hong Kong in the loose reach of Great Britain prior to the reconnection to China? Or like nothing so far seen before, like the situation described in Hart's The 
Warehouse, a law unto itself with its hubs comprising opportunities and borders.

Or we might call it an algorithmic state given the use of Artificial Intelligence, robotics and algorithms throughout Amazon's operations. Algorithms determine price, they determine competition, they determine borders in the sense of what players are to come to market and what are to be kept out as well as how well Amazon's own products might fare in the market all done in terms of speed and reliability of service. And algorithms determine comfort and trust as Alexa meets the needs of clients from the most basic to the most abstruse.

Coming back to the argument about multipliers:

Lina Khan in her Yale Law Review article is suggesting, I think, that through the legislation regarding big entities and the influence of the Chicago School on it the USA has offered a benign environment for the growth of Amazon and not a hostile one at least pre-Trump. This could be said to be the first multiplier for Amazon, the inadvertent growth of an entity initially on the back of but ultimately, from Khan's perspective at least, at the expense of consumer satisfaction, of price. The implication, at least from Khan's writing is that if the flywheel knocks out competition for Amazon's own products then ultimately there will be a false market and an untidy relation between price and value. 
Bezos lucked into the crazed contradictions of a nation-state, the USA, that wanted best prices for the consumer regardless of the scale of the supplier. He maxed that scale in ways not envisaged and created a market beyond other markets that might compete. He took his algorithms to town and came to own the market square.

The second multiplier is the pandemic. Covid 19 has meant that the world starts and ends for many at home and service to the home is Amazon's brief at which it excels and in which it is trusted in an intimate way as part of the family. To consider Alexa I would point to a book called Living Dolls by Gaby Wood who details the history of elementary robotics in forms acceptable and endearable to humans. These range from Vaucanson's's shitting duck to modern Japanese robots. Alexa offers soft comfort, accuracy in our clumsiest moments and the voice of a doll living in extremely close proximity to us. What now given these multipliers and what new multipliers might we see?

In terms of fulfilment of satisfaction Amazon is first port of call for books, goods, services and conveniences of all kinds. And here we go back to immediacy, to wish fulfilment in the momentAmazon is almost in the moment- same day, same moment delivery.

All this with the voice of Alexa, the robotic tool to hand, the extension...Alexa could be the next multiplier, the first of a robot family to be with the human family and to potentially become as 
essential as the bra or the car. Does Alexa open the door to a complementary robot world, complementary to our basic needs? And could this close, this visceral, this immediate voice response be the harbinger of an altogether different type of multiplier, one at least as powerful as the others? Would this go with the rating of ourselves by AI set out in Black Mirror 1 and discussed by Jean Tirole?

It is the view of the present writer that neighbourhood meshes, the shells in space and other features might be amongst the 'new multipliers'. These are discussed in later parts of the Two Suns? series.

It is asked whether the study of hubs is critical now especially to consider how Amazon controls as well as offers its hubs. And later the idea of a typology of hubs with reference to Berry's work is considered. There is also the consideration of the scale of Amazon and its operating criteria:

Does Amazon use the same kind of criteria for inclusion and exclusion in its market? This question gets us into whether Amazon is a predator that welcomes stall holders into its market and then proceeds to copy and then exclude exclude them.

As One concludes by running over the points above there are some thoughts about screen and cloud: 
Then there is the screen. The first port is the screen on the computer or the phone and then its on to ports at hubs to suit the consumer. Then there is the cloud, an external authority, unseen and unknown in its potency but trusted nonetheless.

There is also the general picture:

Then there is the overall context ...; 5G, Yuah Wei, Alibaba, Huawei, China, Oracle, Apple, Gates... a brief consideration of the China-USA divide over tech, over TikTok and the like might lead again to the thought that either place, either state, the USA or China offer impediments to client service so as to form a hostile environment for Amazon.

And finally the idea of strangeness in a sovereign context with a look at the derivation of the title of this series:

In both cases Bezos and the Maori King are made strangers at home. In the nineteenth century this happens to Maori through disease and war and for followers of the King Movement the confiscations and the exile to the King Country that followed the war in the 1960s. In the case of Bezos he has become an enemy of Trump with attacks on Bezos' ownership of The Washington Post and the cutting of the Pentagon supply contract. Could alienation from the home state, the host state, as it were, become a multiplier as new grounds for growth are 
sought and found? The placement of hubs, in this sense, becomes critical.

Finally, ...regarding the sovereignty issue of 1905 , railroads and all that mentioned by Khan and then by Streitfeld of the New York Times and also by Dumaine. Sir George Grey's question of the Maori King at the outset of the Land Wars in New Zealand, 'Are there two suns in the sky?' might apply...

The next parts of the Two Suns? series run over and go backwards and forwards through the above points adding additional thoughts along the way. These parts are known here by their numbers in sequence, Part Two or, simply, Two is called 'Of Kings and Cobots'.

It is argued and asked at the outset of Two:

The argument so far is that Amazon, the creation of Jeff Bezos, is an entity of a scale and compass to invite comparison with organisations bigger than the company and, in some respects such as the trust of the client in Amazon, like the state. To what and to whom might this kind of trust in a person or an entity or a process such as that described as Bezonomics be compared?

Definitions of words like 'state' and 'trust are worked over and there is a puzzlement stated regarding 'shelter' and 'security': 
Amazon does not seem, overtly at least, to offer shelter and security but perhaps there is a covert process through Alexa and other systems that offers these in a new form. It has been suggested that Alexa cuts into and exists in and grows in an area not much occupied so far by the state, close to the human body in a doll like form evoking the film Ex Machina (2014) and the book Living Dolls (2002).

After considerations of centrality (Does Amazon appeal as a central agency?) the discussion goes to the authority of data:
Above all there is the authority of data and the best ways to use data. This comes down to having the most data and the best logarithms. With this in mind there are several players, Amazon being at the forefront. One thinks of Alibaba, of JD and a few others with considerable if not outrageous, in certain cases and respects, authority. 'In data we trust', say the boffins at Amazon and so does the clientele, the customers, the citizens in this polity of trust.

There is a consideration of Amazon in the wide world and some of the ways it deals with problems abroad and in the Case of the Stop Bezos Act, at home in the USA:

Another example might be with Bernie Sanders and the Stop Bezos Act in 2018. This was meant to 
stop Bad Employers Zeroing Out Subsidies. The first thing to note is just how big a player in the USA is Bezos to have an Act named after him in this way albeit as an acronym. The second and more important substantive matter might be whether Bezos does or does not look after his employees in the USA and I leave that hanging simply because, as Dumaine (ibid 248) points out it all gets a little academic as so many jobs might be taken by robots. The real issue might be automation.

And Brian Dumaine's point about robots is extended with the discussion of 'cobotics':

Here there is something of a crossroads perhaps. How long will it be before robotic systems prevail in the fulfilment centres. Now there is talk of people working from home to control robots, of drones doing inspection work of the loading and packing processes. If people become redundant in the workplace will they become a kind of consumer farm supported by Universal Basic Income to enjoy the fruits of the factory?

A distinction is drawn between cosmopolitanism and the interests of the nation state:

Yet another example of authority at the nation-state level or between nation-states is that in October 2020 when a Singaporean arbitrator ruled that in India the partner of Amazon had breached arrangements with its local partner, Reliance, by 
getting involved with a local third party in such a way as to breach Amazon's deal with Reliance. While this seems to be a victory for Amazon this issue points to the conflict between what Ulrich Beck (Beck, 2000) calls cosmopolitan interests and those of the nation-state.

Again:

This raises the question; where should Amazon be based? It does not behove Amazon to be beholden to any given state if the flywheel is to find its best form, a condition without impediments. There is the discussion of New York or elsewhere in various parts of this mini series as a centre for Amazon. Could or should Amazon be based outside of this earthly frame in cyberspace or in outer space? We might note the plans and beginnings of low orbiting satellites which might connect internet to all robotic systems through the Kuiper satellite system. These questions are considered as this mini series goes along.

Looking ahead to the definition of The Algorithmic State put forward in the Two Suns? series.

We could suggest that Amazon, with the emphasis on the customer whoever that might be and wherever the customer might be found, fits the ecology of the nation-state or context that it finds itself in. The EU is a different context to the USA and there is algorithmic adjustment accordingly. 
This is a little like Sahlins (1958) and the high and low island ecologies of the Pacific and the different cultural features in each including kinship. India is not the USA even if, as seen through Singaporean or other eyes, it ought to be the same. It is always a question of defining the best entry and exit points and strategies in any and all market contexts with the objective of maximising Amazon's interests. Sometimes, as with Ulrick Beck's cosmopolitanism, the terrain might be flat and sometimes in specific nation states there might be specific contours to meet, mix and match.

In all of this who is in charge and how does that work?

To come at the question of authority...Bezos seems an unlikely King. This is partly to do with his personality which sometimes seems more like the guy next door doing technical stuff in his garage than a monarch. But also because sovereigns are usually defined by their realms. In the case of Amazon the realm is not a country. In fact, the way the algorithms work is to treat any kind of border, be it one of price or distance or anything else, as a challenge to be overcome. The algorithmic state works back to what the algorithm can learn and apply rather than to an accountable political, social or spatial authority. Governance over is governance from a point of origin not from a point of extent, taking us where it may in the most effective fashion, 
effective in terms of the rationality set into and then learned upon by the algorithm at base.

Later I will come back to the proposition that the context of home and market informs or presages a new form of citizenship. Amazon pervades the lives of members and invites talk of a culture, of a world of satisfaction. The evolution or progress of states and their empires has often involved new combinations- administrative systems and law with the Romans, naval capacity and effective communication with the British in India or the Dutch in Indonesia for example. In this case the new combination is of multiple presences- in the market, in the home, in the cloud, the presence of service getting better through algorithms all the time.

How tight or loose is the culture over which a King presides? The argument here looks forard to the discussion of techno feudalism in Six:

Amazon is a bit like all of the comparisons and contrasts above. It may be seen from various points of view. And each point of view has its own significance, looks at a distinct sovereignty or domain which link or at least sit beside one another in a jumble. It may be that Amazon is at the point where cross fertilisation across diverse areas is occurring. For example the systems in Go stores where customers pick up and do not pay at the checkout as their information is logged through their phones may be useful in the Fulfilment 
Centres. Alexis is said now to be integrated into some twenty thousand devices and, as noted elsewhere in this series, is riding a wave of development in voice recognition whereby voice could replace text in many ways.

While the latest gadgets are mentioned and the varied use of such things as drones in various Amazon places the overall point here is:

Rather than a poorly assorted jumble of features though there now seems to be a set of integers in Amazon, a cross-referencing and cross fertilisation that takes us back to the idea of the multiplier, this time to a kind of quantum effect (cf.Venture City Amazon's City of the Future 2019)

Coming back to citizenship there is the comparison beyween being a member of a club or a member of a state which runs through the Two Suns? Series:

From one point of view, Prime, Amazon is a rewards programme operating through a company card. But it offers membership which is extremely far reaching and, through Alexa, extremely intimate. Combinations through Prime, the main club, are important Over half of Whole Foods customers are Prime members. Is this the real reason for the purchase of Whole Foods? The combined memberships go with, complement and extend the cross fertilisations suggested above. There is after Clifford Geertz (1973), a thickening of things. 
Interestingly, the idea of thick data is put forward later in the series, notably in Seven where the drawing of a person as a data doppelganger and their subsequent treatment is discussed perhaps with Geertz in mind.

Then it is on to citizenship and happiness:

Is this kind of extensive, multi-faceted membership alike to citizenship? You join one club and gain access to another and another, to satisfaction without apparent end. In an interview from 2000 Bezos is backing Tony Hsieh's company Zappos. Hsieh has written a book entitled Delivering Happiness. Bezos is talking about inventing your way out of the box, of inventing on behalf of the customer. Is Amazon a Happiness Club? Amazon acquired Zappos in 2009.

The emphasis on happiness and satisfaction evoke the work of Neil Postman in his book Amusing ourselves to death (1965) regarding television. The sense of immediate gratification that television gives has echoes in the happiness and satisfaction for the customer that Bezos and Hsieh seek. We might go to Aldous Huxley's Brave New World (1998) while we are at this point.

What kind of tax are people prepared to pay for happiness and satisfaction?

Coming back to the idea of agency do we wonder what Bezos himself might do for us or do we have respect for his data and the way that data is used 
with, as far as we know, the best algorithms, the best ways of satisfying us?

When we speak of Amazon in terms of agency what do we mean? Are we talking about Bezos, about Amazon as a corporate entity or about the algorithms involved? Who or what are the critical actors? Are things in our life caused by Bezos or do we control things with his apparently unlimited help? Or does Amazon simply invite us in to a world of algorithms operating across our fields of experience? In this view the algorithms exist to maximise or happiness, to increase our satisfaction and they form the critical agency.

Bezos does have his theorems, thse are somewhat folsy, sometimes pithy sayings, phrases or terms. It is argued in this series that these migght be misleading but they are explored as in:

In a talk at the George Bush Center in 2018 Bezos outlines four key points. The first is customer obsession where the customer is always pulling you along and this is distinct from being competition focused. The second is eagerness to invent. Next there is the long term thinking of 5-7 years and the last is operational standards. Bezos also refers to sufficient scale and speaks of a cultural thread. He also talks of having a 'deep keel'.

This array of folk axioms will no doubt be used in the next ventures one of which will be space and this 
is mentioned in Two but developed for discussion in Four:

Its all about price in the long, sometimes very long term. Bezos, in the interview with his brother argues that the main obstacle in space travel is price because a rocket might only be used once. The problem to be solved is how to use the same parts of or the same rockets to launch into space.

More terms are considered such as 'flywheel' and 'Day One' and there is a critique of the city as a primary or the primary hub in the day of the rural Fulfilment Centre and the drone.

The idea of consumer farms and the reference to Susskind's advanced capital look forward to the discussion of techni feudalism in Five. This goes with the discussion of cobotics where robots are increasingly working with humans or vice versa.

Then there is a discussion of how Amazon is now working across nations and this looks forward to the discussion of Neflix later in the Two Suns? series. It is suggested in the example of sinofication below that sovereignty, the sovereignty of nation states is now somewhat redundant:

Then there is the question of whose influence is being multiplied in the Amazon context, what multiplications, planned or otherwise are there within the multipliers so to speak? Is a sinofication happening with Amazon.? This company started in 
a given state, the USA. It offered, amongst other things, a platform, a market. Amazon's citizens were US buyers and sellers. Then there were US brands produced in China. Now that market is being dominated by sellers with their own brands from outside the USA, from China. If brand and price work they might be taken on byAmazon, bought out or replaced. At least that is the way it has worked to date. Will the prospect of Chinese preponderance in the market change this process? In terms of sovereignty there might be a parable here, the parable of the Chinese seller, firstly in the American and then in the global Amazon market. But has Amazon become or is it becoming a Chinese market? Before the Chinese manufacturers made articles for sellers on Amazon and after they became the sellers themselves. Bezos encourages this with Dragon Boat and in 2018 one third of sellers on Amazon were Chinese. There have been complaints about Chinese hackers pirating other people's data which is gold in the Amazon universe. Have the Chinese competitors figured out weaknesses in the algorithms?

Putting this another way without reference to cultural or political identity or to sovereignty of a national kind, is understanding the algorithm the key to management now? And is such understanding the way forward with multiplication?

Part Two of the Two Suns? series concludes with idea that Amazon may be a shadow of a state. 
Part Three begins with a reference to the Gilded Age and a suggestion that the Age of Big Tech is comparable only of a larger scale.

At the same time it might be worth considering where things are not working as well as they might and there is a discussion of things like 'deep bin picking', 'the last mile', 'facial recognition' and other things that are 'work ons'. Most of these things seem to be being achieved is only in a series of small steps sometimes in different places. For example there is the outlawing of facial recognition in the USA but not in China.

On the other hand, Amazon now offers a multiplicity of developmental points and that in itself is a kind of multiplier. Here we have a scale of diverse activities as well a sheer scale of volume.

But some things still do not gel and the example of drones is given. At the same time we might be able to speak in terms og the great grid:

These loose ends, these ventures that have not quite arrived belie a sense of system about Amazon. We may not understand it fully but Amazon seems to leap and surge in ways that satisfy us. Let's think about Amazon as offering something like 'the great grid'. Just as the railroad cartels in the Gilded Age offered a great grid of efficiency across America where before there had been a mishmash of companies and players Amazon offers a data zone which is sufficiently organised to satisfy us better 
than anything else just as it tantalises us with things it is reaching for but not quite grasping. We might go back to Edmond Morris and his book Theodore Rex (2002) for more on the grid, we could go back to Lina Khan (2017) and the idea that the world is running on Amazon's rails and note that things are more international now. There is an internet that surpasses the nation state so that the boundaries of the railroads contained within nation states may not apply. As we read further we might turn to Becks's work on cosmopolitanism (Beck 2000) and ask whether the algorithms work to effect cosmopolitanism and reduce nationalism or at least to reduce the bounds of the nation-state.

We may have to come back to fundamental questions:

Basic questions of society and politics come to mind. As citizens people are members of a nation state. As customers they might be members of a club, a rewards system. What is the difference between the two, or the similarities for that matter, between what Amazon offers and what a state offers? Here the answer offered is that they both offer satisfaction for the human condition. We need to have clarification for both parts of this, what do we mean by 'satisfaction' and what do we mean by 'the human condition'?

Coming at the question in terms of the algorithm and the human with another question, is the latter cobot or consumer? Or both? Might we speak of a 
cobotic condition in which humans depend on algorithms through the likes of Amazon and make decisions, political and otherwise informed by AI and algorithms? Can algorithms learn progressively about the human condition and increasingly satisfy human needs? Might we be talking about consumer farms with people on Universal Basic Income supplied by algorithmic and Artificial Intelligence operations that extend to food production as well as other human needs as time goes by, consumer farms that function, primarily to consume with the occasional tilt at being cobotic?

The fundamental questions continue:

Basic questions of society and politics come to mind. As citizens people are members of a nation state. As customers they might be members of a club, a rewards system. What is the difference between the two, or the similarities for that matter, between what Amazon offers and what a state offers? Here the answer offered is that they both offer satisfaction for the human condition. We need to have clarification for both parts of this, what do we mean by 'satisfaction' and what do we mean by 'the human condition'?

How will we know all this? How will we know geopolitics? Through nation-state or borders or techstate areas of influence? 
Talking of Walmart and Amazon, there is a division, a partition of America and the world somewhat like the partition of Africa in the 1880s. Sometimes this is to do with having warehouses near cities. In the USA Amazon takes the coast and Walmart takes the area between. Across the globe Amazon shares space with, say, Alibaba in parts of Asia. Is this like tribalisation or retribalisation where new configurations of power in specific and not so specific places happens with new combinations of interest and locale? To carry on with physical space being divided on a global basis, Alibaba and JD take China, Amazon has Europe and shares Britain with Tesco. India is shared between Amazon, Walmart and Alibaba.

And there is the non-specific space of the internet, of cyberspace, of the cloud. How might that be divided or made into sectors? Then it is on to outer space, To what state will the trillion people imagined by Bezos to live in his version of space exploration belong?

But even with physical, geographical space there is no Berlin Conference, no grouping of great companies to sort out who goes where apart from isolated cases like the German Example, The EU Example or the India-Singapore Examples mentioned above and discussed throughout this presentation. The algorithms employed will find their own niches, work their own spaces, eat their own data. 
Its about time and space, the latter being intriduced in Three but developed in Four and across the Two Suns? series,

We might talk about time as well as physical space. Is Amazon offering service forever? Service over space and time? One thinks of Bezos' 10,000 year clock. Also of what I have called the Amazon paradox or apparent contradiction of staying in Day One for the long term.

And as well as physical space on this planet there is the mission of Bezos in space which is to save humanity from itself on earth. Here you can see an ideology in Bezos which goes beyond making the next dollar in a faster, more efficient way. How do algorithms fit into such a vision? We could go back to questions of anchors and orbits. What are the anchors based upon? Where are they set? What are the orbits going around? Where is the best developmental space for Amazon? The algorithms are learning the answers.

The Amazon saying or mantra, 'In Data We Trust' is mentioned and, of course, this is axiomatic.

The entry to health services seems to have been a problem for Amazon but coming back to the idea of entering the health field, one door seems to imply the opening of another. The Amazon health Savings Card takes Amazon further into banking with 1Click. Savings and banking offer another doorway. Amazon is already lending to merchants in 
American markets. Amazon owns a Visa card with Chase and people could ask 'Hello Alexa what's my bank balance?' A step into convenience here, a step there into happiness there, the algorithms figure out the satisfaction equations and become, as they do so, the authorities, the go to agents. The owners of the algorithms, 'these guys' themselves, become cobots in the process.

And then there is the sheer scale of things:

What is the scale here? Dumaine goes back to the Dutch United East India Company from 1602 until 1799. This is important as we see a small country and a big company and we could refer back to the points made about Nauru and the Cook Islands in Part One of this series, These mighty corporations lasted for centuries based in small countries and there was not, then at least, the need to be in a big country like the USA.

Looking ahead to Seven there is a reference in Three to notions of the self:

All of this pertains to notions of the self as well as the state and I refer to earlier work on the remote self (Cleave, Books and Books No 31). Alexa has potential in the self image area and we go back to Black Mirror Season Two Number One and also work by Tirole (2020). What are the personal identity needs serviced by Amazon? It is argued that the situation of the individual and the group is 
critical and that Alexa may be the most potent and original as well as life-changing portal that Amazon has offered to the client to step through. Again we come back to the state and the machine in terms of the self. The machine in this case is the algorithm... So many philosophies are at stake. The idea of externality, for example, with the person relating and in some respects now deferring to the algorithm. This might put us into a consideration of self, the volitional self or the passive or dependent self or even the received self. The self as a (Western?) conceit. There is a sense of realisation before conceptualisation- people depend on Alexa before thinking about what Alexa is and what she might bring beside the happiness of the moment.

It may be a matter of self and machine:

Having nodded in the direction of happiness with Huxley, Hsieh, Postman and others in mind we might look back on Wells and others in the science fiction universe and see that that they got the machine thing right, the machine in service and the service to the machine, in certain respects. Algorithms are showing us who we are. The algorithm is learning from the client organising the shape of self as indices of happiness, personality and satisfaction are formed. There is a shaping of consciousness, of the awareness of the self in groups following Tirole (ibid) and thinking about bundling. 
And, again, how do we know all this?

We could come at this from a knowledge perspective. As Foucault (1994) saw in the nineteenth century the emergence of man so we might see here the emergence of man and machine, of the cobotic situation, of the extension or incorporation of machine into mind. Foucault's idea of a break in the table where man became the centre of reflection and the divine plane did not reflect truth upon the populace as an external reference for the good now changes as man reflects on the feedback from the algorithm, the algorithm extends and the knowledge universe comes to have scope and dimension not hitherto imagined.

Does this play so that the church was the point of authority outside the man and all that has happened is that it has been replaced by the machine outside the man? Who or what is the deus and what is the machina? Or do we have a new field of knowledge?

Is it a matter of mind?

All of this pertains to mind. We might think of the role of algorithms in social memory and memorialisation. Taking the last first we could say that Alexa reminds or could be asked to remind us about other peoples' birthdays as a starter. Beyond that there are the references to memorial days as well as the jogging of the memory about, say, Prime Day. Here we see a potential conflict between 
reminding people about Prime Day, an Amazon feature, or Singles Day, an Alibaba feature. Whatever, there is the construction of a significant past using an algorithmic process.

We could turn to several theorists here. To Kenneth Foote's excellent work on memorialisation (Foote 2018) or to Li Min's work on social memory and state formation in early China for example (Min 2018). The latter might be important for the argument in this miniseries concerning the algorithmic state. How are our beginnings and ends, our key concerns and beliefs, our main events conveyed and reinforced through Alexa and other features of Amazon that run on algorithms?

Part Four of the Two Suns? series is entitled The Data of Nations and this is a play on Adam Smith's work The Wealth of Nations of 1776.

We might start by going back to what the deal actually is between the client and Amazon and the role of algorithms in it. The deal might best be seen, in its first form, in the joining of a club. The club is a data club, the most extensive in the world with the best farmers of data, the best algorithms. The key club, the main portal, if you like, is Prime. We go through the club doors to a rewards programme. This morphs and spins into a universe of power and control. Data is potential power and the algorithms are ways of realising control of that power. 
As Dumaine (Dumaine 2020: 216) says Amazon has unparalleled technological firepower. The flywheel is driven by massive amounts of data. Who owns data? Amazon owns all pricing and product data going through its platform. The adage that knowledge is power takes on another sense.

The data of nations is in Amazon. If data is money Amazon is a major bank- amongst its data peers like the World Bank in terms of currency perhaps... ...could Amazon withhold or control data in such a way as to influence nation-states?

But with space being a key field for big Tech operators with the Amazon and Spacex shells discussed later in the Two Suns? series:

...we might also come to think about a situation outside of states as they are known on earth. For example the creation of a set of satellites above the earth providing internet and other services may be seen as an exoskeleton outside and away from state, interstate and state and business interaction. If the data is collected and shared by a web of entities outside the space and air of the earth then even the phrase, 'the data of nations', starts to lose force.

\section{What combines with what here?}

Is the key pairing here between Amazon and the client, between the algorithm and the client or simply between algorithms? Cobot to robot, cobot 
to cobot or robot to robot? This takes us back to the consideration of agency. If the key pairing is cobot to cobot we may be at the point where the machine leads the dance and if the key pairing is robot to robot humans might watch the dance from their consumer farm. If the key matter is happiness then, after Huxley (1998), Hsieh (2013) and others we smile as we watch or join the dance. If the key matter is memory, social memory, then, after Foote (2003), Min (2018) and others we may be jogged into a sense pf past, present and future by the dates, by the shapes of time we are fed.

As Four progresses different kinds of space are considered:

There is the space of the shop, the space of the warehouse, the space of the country and with drones the space of the sky.

And then there is space as in outer space. Bezos, Amazon and the algorithms associated are in all of these spaces and rationalising, as it were, one in terms of or against the another. Regarding data the issue might be where it is stored. If it is stored in outer space in satellites then we are outside of nation-states just as we are outside of the earth. The data of nations becomes an obsolete phrase perhaps.

In the later parts of the Two Suns? series, especially Five, the neighbourhood mesh is considered and in Four the discussion of Alexa foreshadows that. The 
closeness of Big Tech to personal space is new and important:

Alexa offers an experiential, visceral presence of a kind that we do not yet know the dimensions of.

Like a lot of Amazon matters its a matter of finding the dots and then connecting them or letting the algorithms find the connections and work out the agencies. Then it is a matter of consumer satisfaction. Over time. In a sense the algorithms themselves are the agencies to determine what is to be delivered and how, when and with a sense of satisfactory experience. The algorithms learn the consumers needs and how, when and why they might be satisfied, robot to cobot as a new consumption cycle comes into being.

There is then a discussion of happiness which is returned to in Seven especially with a consideration of the self:

But the idea that there is a revision of state processes and thinking about the state carries on, Here we have, on the face of it, a statelessness. The states of earth have been left behind. But perhaps the states of earth were already left behind with developments by these players and others in cyberspace. Perhaps, beyond the face there is an incipient form in a new kind of state to be.

But we have to keep out feet on the ground perhaps: 
Coming back to earth there may be a new form of multiplier in the relation between hub and algorithm. We have not done the learning yet about rationalising hubs in the most efficient way and we might go back to some of the questions Berry (1996) is asking about tourist and corporate travel regarding hubs as well as other questions. The algorithms will maximise hubs. What will happen to cities when and they are transformed by the Beehive concept with drones operating at the high levels of high rises (Venture City 1019). There is the obviation of roads for a start...

Then there is the classification of power places to use a phrase. The algorithmic state would be a series of linked hubs. How do we think of hubs? As mere warehouses or as critical points in an infrastructure of state? A most rudimentary typology of hubs has been offered here and it is important perhaps to note that algorithms operate inside hubs monitoring and directing workers (Hart 2019, Venture City 2019). A comprehensive typology of hubs could show the range and diversity of uses and activities involved and to come back to the idea of skeletons we might be seeing a redrawing of the body economic as well as the body politic in such a structure.

There is a consideration of sovereignty with reference back to the New Zealand context and the Treaty of Waitangi: 
One strand of the argument here has been that Amazon offers a glimpse of a new consciousness a new sense of sovereignty perhaps, as people grapple with new conditions in a tired political state. This is a sovereignty game, a process of finding new political forms in the expiration of older ones. Amazon or at least the algorithms that it employs and that structure it are giving shape to this new consciousness. The game of sovereign chance where two groups entered the Treaty of Waitangi, each entering an unknown space applies to tension between cosmopolitanism and the nation state as it does to the notions of cobot and robot.

Following a discussion of the term algorithm and matters like tax in the conclusion to Four there is a return to the idea of two suns:

We could come back to the idea of two suns with a question mark behind the phrase. In the first of these talks I referred to Governor Grey asking of the Maori King, 'Are there two suns in the sky?' We could look at Bezos and Trump and ask the same question which might take us to where Amazon might be located, in or out of the USA. Just as there was an argument cited above between Giancarlis and Carney there might be an argument about whether a given city such as New York in the USA is a good context for Amazon and its algorithms.

Similarly the two suns might be Jack Ma of Alibaba and Jeff Bezos of Amazon and a further set of questions ensue probably more to do with who has 
the best data and the best AI systems to deal with that data. This takes us back to the data of nations argument above.

And we might, at another level perhaps, ask whether the two suns are robot and cobot. Here we go to the literature and the movies with considerations of Alexa, with thoughts about Ex Machina (2014) and the book Living Dolls (Wood 2002) as entry points to such a discussion.

Proceeding to Five this part begins with a citation from Cathy O'Neill about algorithms which is worth repeating as a cautionary:

Algorithms are opinions embedded in code. It's really different from what you think most people think of algorithms. They think algorithms are objective and true and scientific. That's a marketing trick. It's also a marketing trick to intimidate you with algorithms, to make you trust and fear algorithms because you trust and fear mathematics. A lot can go wrong when we put blind faith in big data.

- $\quad$ Cathy O’Neill Tec Talk 2017

The above is something of a classic statement in the literature discusssed in Five and elsewhere in the Two Suns? series. With this in mind the role of Big Tech in nation states big and small is discussed and the suggestion that we are looking at techno feudalism is made. A definition of feudalism by Hirst 
is examined for and then a thesis by Kotkin that California is an example of techno feudalism is discussed.

Along the way leadership is considered:

To take leadership for example, we are talking, as Giridharadas (2019) suggests, when considering Bezos or Zuckerberg of Amazon and Facebook respectively, of new styles of leadership. This might be called digital leadership. It is not voted in. Does it emerge from the sort of culture described in No Rules Rules a book by Hastings and Meyer on Netflix replete as this book is with phrases like 'instrumental control' and 'internal context'. Is this 'culture' also found in such phrases as the two pizza rule' in what Dumaine describes as Bezonomics simply a mask for control of data?

And again, does this set of contours/shapes/different contexts (shells, hubs, cyberspace etc) generate or allow forms of leadership, kinship or citizenship? If so what might these be and, also, what might the preconditions for such be? Furthermore, do they really conform to an idea of feudalism or is this a new form of organisation? Regarding the law:

...it may be that we would do well to look at Big Tech and the law. This may be seen in the Milan school and their idea of the algorithmic state in which the law of nation states is fundamental. Also the Yale 
scholar Lina Khan is important in such a consideration as pointed out earlier and discussed later regarding the Sackur-Khan interview on the BBC. Khan's fear that the weakness of anti trust legislation or at least the strictures on that legislation via the Chicago School allows power of a new kind to occur may relate to this idea of preconditions for feudalism occurring in law. Such an argument rests on the weakness of the law in the case of techno feudalism whereas, in the Hirst argument at least, there were matters in the law following the alteration of the common law after the Norman Conquest that supported the growth of feudalism.

Then there is truth:

Just as control of entertainment is important, going back to Orwell so is the control of truth. One aspect of techno feudalism that sets it apart from earlier forms is the power to lie. Not only does Big Tech own the data it also controls the algorithms that, as we shall see, after Sauter and O'Neill and others as this series develops, can spin the data. The person on the street without data of scale and without the use of significant algorithms cannot do this and because Big Tech owns data and controls algorithms on a scale that many governments do not then Big Tech becomes, after Orwell, the Ministries of Truth.

Regarding leadership: 
Proceeding from the historical account is the homespun idea tech leaders in startup mode as with Bezos in a garage with one partner, Zuckerberg and one or two others operating out of a student dormitory or whatever and the general spinning of a digital leadership myth after Horatio Alger. This myth is discussed further in this Two Suns? series and is well treated by Anand Giridharadas.

An example that would seem to follow the model Kotkin sets out in California is given:

Throughout this series an effort has been made to scope the minority situation especially where there is a state within a state situation. As a critical thought we might look again at the 'no knock on effect' where there is no trickle down or cross over of benefits from one community to the other. In New Zealand there are two communities side by side in the Bay iof Islands, one that might be described as tech savvy in Kerikeri while adjacent is an extremely poor community without tech in the form of computers, without resources generally and without running water in places.

Then it's out of California to the world looking at the idea of techno feudalism as described by Ramon Bleuca. The title of Neil Godfrey's paper 'TechnoFeudalism - We are working for Big Tech for free' opens up a discussion on Facebook which really 
illustrates the serfdom that the public are engaged in.

A short critique of the idea of techno feudalism is offered:

Tempting as it might be to accept feudalism as a guiding light for analysis we might also look further afield for useful forms of analysis. We could go back to Weber and talk about charismatic leaders and theories of charisma when think about Bezos, Musk, Gates and the like. Or are these leaders simply riding a new form of capital which is data ('in data we trust') combined with efficient algorithms. Is the success of Big Tech to do with governments not owning data while the big tech companies do? Is a data bank comparable to a treasury?

Then there is a look at culture and the arts in a feudal situation:

Is there an equation or a similarity between nobles and their courts and say Amazon and Prime entertainment. Did each noble provide some circus as well a little bread to the serfs? Do the serfs come to naturally pivot to that type of entertainment with its stresses and its absences, to their accustomed 'culture'?

Do the nobles run plays where they select the scenes and instruct the playrights? Do the nobles say who to invite and what story to tell? Then there 
are the studios as well as the court theatres. How to paint as well as who to paint and in what light? Amazon owns Prime and controls the narrative there. Who to invite and what they might say. How to cut the movie today in the Amazon-Prime world might be like how to paint the portrait in the world of the feudal noble. We could digress into a discussion of Las Meninas and the role of the artist in all this.

What about the sharing of knowledge and power by a few?

So we have a set of players who tend to find a centrality to what they do. This may be cultural practice. We could note again the influence of Collins and the workaday formulae of the two pizza rule at Amazon or the Netflix Innovation Cycle. The central shared features might be found in entertainment and the analogies of court theatre for nobles and Prime to Amazon might be noted again. Or it might be usage of a state apparatus as Silicon Valley uses California and most Big Tech operators use the USA as a home. But in all these cases and elsewhere perhaps there is a tendency to find common ground, to 'shadow' one another to go back to Cheryl Sandberg of Facebook following Reed Hastings around the Netflix operation, to find and savour the 'secret sauce' as Jim Collins puts it, of one another. 
Then there is the use of management theory as in Bezonomics and the influence of Jim Collins there and in Netflix and elsewhere. How does this compare to ideology in the context of feudalism?

Then there is the sharing of management knowledge, the other end of the 'culture' which is the nobles running the serfs, Silicon Valley and the rest in California. In their book No Rules Rules, Netflix and the Culture of reinvention Hastings and Meyer (2020: 130) cite a visit to Netflix from Cheryl Sandberg of Facebook who follows Hastings around at Netflix in a 'shadowing' exercise as she takes notes and keeps quiet. This is like farmers sharing walks around the farm with other farmers. It is standard practice as the book implies. It is like Nobles attending jousting or theatrical displays or dinners, all places where the culture of feudalism might be shared.

What after all this is the Algorithmic State?

We might talk about the contour or shape of the algorithmic state and then the profile of operators in that context. For example the contours might be shell, hub, cyberspace and screen with several points between these. The profiles might be that Amazon operates in space with a shell, works extensively with hubs and cyberspace and uses screens. It has a profile across what I have called the basic contours. Facebook does not operate in space but has a major presence on screen and in 
cyberspace. With these two contour shapes in mind we might turn to Eion Musk and Tesla and talk about another contour shape with strength in its shell in space but not a great presence in cyberspace. As this article and the ones that follow treat these shapes it is suggested that these are shapes of state, of algorithmic state and such concepts as tech feudalism might inform the general model suggested.

We might take these shells as one of a set of distinct physical points. Another might be space or sky very close to earth where drones deliver items. One idea which seems logical is that drones might deliver to the top of lamp posts. from here goods might be dropped to scouts that in turn deliver to houses. The drones recharge their batteries at the top of the poles as or after they drop the item.

These points are connected via the internet and to consider the process of connection we might start with the screen in the house. From there all points so far mentioned are connected.

Each point is a learning point. The screen organises information and improves it. Machine learning occurs at each point. There are plans at each point, the plan of Geoff Bezos to settle people in space for example which might proceed from the Amazon shell. The series of physical points and the information processes involved constitute a new 
form of state, a new structure or infrastructure, if you like.

There are matters of externality and mind. With the learning involved outside of human minds the Algorithmic State literally thinks on its own. One algorithm serves another and learns in tandem and sequence with others.

Some points are outside the scope of the nation state at least as this is commonly known and these are the shells of space and cyberspace. We could go back to Bezos and his vision of space settlement and ask whether people would be settled in areas owned by nation states on earth or in open zones, so to speak. Here is the frontier. What will be the shape of the state here?

How do we understand all this? Coming to Part Six, The Algorithmic State: History and Theory the argument here is that a new sense of history is required, one that takes into account and contextualises things like machine learning and developments in AI that pertain to the use of algorithms and the functioning of contemporary economy and society.

We could talk about the industrial age and the information age and suggest that we might have missed the essential industry of the industrial age which became the industry of the algorithm, of a system to take a formula of analysis, repeat it and 
improve it, then proceed into extrapolation, to learning.

Regarding history as we know it:

We do seem to have set of silences, of historical glitches, of missed gear shifts where almost out of nowhere comes a Bayes or a Babbage. And then another gap and then its Learning Machines/Machine Learning.

So Six is a recounting of steps over time. Tedious as this might be there seems to be a need for education as well as consciousness given where we find ourselves today with Big Tech.

This history is important as as we come to reflect on our position in the environment we live in and consider our sense of self, this being the subject of Seven. As Six progresses there is attention to concepts of law as with the Milan school regarding the Algorithmic state and another look at Lina Khan last considered across One through Four.

The argument in Six is that we need to look at the history of AI and Machine Learning. A skeleton of dates is given which, it is argued, is not often considered as central but which could well be considered as critical, central points in a new historiography. 
The way people grapple with this history if they do so at all is usually with reference to the nation state. Understandable as this might be in the analysis of the Sackur/Khan interview it is suggested that such a framework is limiting and somewhat of a distraction. Going back to the discussion in Two Suns? Five we might see this history in terms of the development of Big Tech and think again about Kotkin's thesis of 2020 that California is moving into techno feudalism.

We might also consider the rise and development of the internet in our history in order to understand, Facebook, Netflix and other Big Tech operators. As stated in the conclusion to Six:

It has been suggested in this section that a mind shift is required to a new sense of culture and history. The machine, the learning machine could well be central in such a consciousness. A detailed history of AI, robotics and learning machines has been offered via Wikipedia to suggest something of a central thread.

Seven begins with a discussion of the self in the neighbourhood mesh with a consideration of Amazon Sidewalk known and conducted through the Alexa motherboard. Questions are asked: Is this a soft invasion by Amazon? Sold as promoting 'a smart neighbourhood'. Sold by the cuteness of keeping track of the dog? Is Amazon grabbing the 
public space? A takeover of community sovereignty? And a tentative conclusion drawn:

The point might be that Amazon is in the space of the family with the door and the mailbox. This is physical, personal, family space and not a matter of just cyberspace. Amazon is grabbing the locale, securing the neighbourhood, proceeding from the nearness of Alexa to the close proximity of the gate to the closer point of the door as the mesh widens to the sides and neighbours join in an apparently discreet way so that they do nor share information amongst themselves even as they allow Amazon access to their data.

And then with tilts to things like Facial Recognition, it is on to Cathy O'Neill and Molly Sauter:

Regarding the general feed of information to the individual from the net, to what extent is that information and experience true and correct and to what extent might it be rigged? We might turn to Cathy O'Neill who suggests that the era of blind faith in big data must end.

Along with the doubt that Cathy O'Neill so effectively and correctly sows there are also thoughts about governance:

As well as national governance, governance by the nation state, we might talk about community 
governance in the case of the neighbourhood mesh. Then there is the governance of the screen, the individual being shaped and influenced by such forms of governance. Regarding screen governance we might ask about Trump and TikTok. How did that go? Does it show a counter example where nation state governance beats Big Tech governance? Or does it show the difficulty involved in such a governance?

With the above in mind we might consider the self in and across several spaces:

The spaces discussed are, in a sense, spaces of data. And as we find ourselves in these spaces are we also talking about the disregard of traditional boundaries of the self as we are defined, sometimes in a less than comprehensive or, as theorists ... imply, a less than 'thick' way? Where is the self here? In the world of data how do we define the dimensions of the self, of the collapsing and rephrasing of individuality.

In the review of the theorists O'Neill, Sauter, Wang and Vertesi it is argued that there is a shaping of the self and ideas of identity in the world of the algorithm and also that there are a number of coping mechanisms that have been suggested by these writers.

The above has been offered as a chapter by chapter recollection over the seven or eight parts of the Two Suns? series. A number of questions have been 
posed and it is hoped that they generate debate and discussion. To return to the question that George Grey asked of the Maori King, 'Are there two suns in the sky?' in that particular case the answer was and is, yes. The King Movement has continued in the context of or alongside the New Zealand state. The state of Great Britain, critical when Grey asked his question has kept on although it is at a distance now. A final set of questions might be, 'Will there be something similar, a coexistence of a kind with the Nation State and the Algorithmic State?' Are we seeing a situation where several points of power exist, waxing and waning, close now and distant then...? 


\section{Bibliography}

Bayes Thomas, 1763 'An Essay towards solving a Problem in the Doctrine of Chances' (ed. Price, Richard and communicated to John Canton) $\mathrm{Mr}$ Philosophical Transactions of the Royal Society of London. 53: 370-418

Beck, Ulrich British Journal of Sociology No 51 Issue No 3 January/March 2000 pp 79-105

Berry Steven, Carnall, Michael and Spiller, Pablo T, Airline Hubs, Costs, Markups and the Implications of Customer Heterogeneity National Bureau of Economic Research May 1996

Berry, Steven T Estimation of a Model of Entry in the Airline Industry Econometrica, Vol. 60, No. 4. (Jul., 1992), pp. 889

Bleuca April 152021 'Digital feudalism in a multipolar, unstable world' Responsible Statecraft Brunton, Finn Nissenbaum, Helen 2015 Obfuscation A User's Guide for Privacy and Protest MIT Press

Coulon, C 'French Political Science and Regional Diversity', in Ethnic and Racial Studies ed. Stone Vol 1 No 2 January 1978

Cleave P The Sovereignty Game, Power, Knowledge and Reading the Treaty, Victoria University Press 1989

Cleave, Peter $2001 \mathrm{Ka}$ hao te kupenga hiko, he Tuhinga Aronui: the Journal of Maori Writing ed Moon, P AUT 
Collins, J Good to Great, Why Some Companies Make the Leap... and Others Don't Random House Business 2001

Dick, Phillip K 1868 Do Androids Dream of Electric Sheep? Doubleday

Dumaine, Brian Bezonomics How Amazon is changing our lives and what the world is learning from it, Simon and Schuster 2020

Farrow, Ronan Catch and Kill, Lies. spies and a conspiracy to protect predators, Fleet 2019

Ferenstein, Gregory February 26, 2016 "A Lot of Billionaires Are Giving to Democrats. Here's a DataDriven Look at Their Agenda," Forbes, "The Disruptors: Silicon Valley Elites' Vision of the Future," Winter 2017 City Journal, Foote, Kenneth E., Shadowed Ground: America's Landscapes of Violence and Tragedy Routledge 2003 Foucault, Michel The Order of Things: An Archaeology of the Human Sciences Random House 1994

Gadiesh, Orit and Gilbert May, James L 1998 Profit pools: A fresh look at strategy Harvard Business Review May 1998

Galbraith, James "Inequality and the 2016 Election Outcome: A Dirty Secret and a Dilemma," New Geography, July 4, 2017

Geertz, Clifford, "Thick Description: Toward an Interpretive Theory of Culture", The Interpretation of Cultures: Selected Essays, New York: Basic Books 1973 pp. 3-30 
Hart, Rob The Warehouse Bantam Press 2019

Hastings, Reed and Meyer, Erin Netflix and the Culture of Reinvention Virgin 2020

Hsieh, Tony, Delivering Happiness, Grand Central Publishing 2013

Hughes, Chris Fair Shot:Rethinking Inequality and How We Earn St Martin's Press 2018

Huxley, Aldous Brave New World, Harper 1998

Huxley, Aldous 2004 Brave New World and Brave New World Revisited 237.

Khan, Lina M. Amazon's Antitrust Paradox The Yale Law Journal 2017 pp 710-805

Kotkin, Joel Summer 2020 'Neo-Feudalism in California' American Affairs Volume IV, Number 2 McWhorter. John H The Power of Babel: A Natural History of Language New York Times Books/Henry Holt 2001

Laplace, Pierre-Simon 2018 Théorie Analytique des Probabilités Wentworth Press

Lévi-Strauss, Claude (1966). The Savage Mind. Chicago, Illinois: University of Chicago Press Loader, Colin The Intellectual Development of Kat1 Mannheim, Cambridge University Press 1985 Mannheim, Karl 2015 Ideology and Utopia Martino Fine

Min, Li Social Memory and State Formation in Early China, Cambridge University Press 2018 Minsky, Marvin and Papert, Seymour 1972 (2nd edition with corrections, first edition 
1969) Perceptrons: An Introduction to Computational Geometry, The MIT Press

Morris, Edmond Theodore Rex Random House 2002 O’Neill, Cathy 2016 Weapons of Math Destruction, Crown

Orwell, George Nineteen Eighty Four Secker and Warburg 1949

Patterson, Scott, 2013 Dark Pools: The Rise of the Machine Traders and the Rigging of the US Stock Market, Crown

Pierre D B C Lights out in wonderland, 2010 Faber and Faber

Piketty, Thomas 2014 Capital in the Twenty-First Century, trans. Arthur Goldhammer Cambridge: Harvard University Press

Pocock, J G A Politics, Language and Time Essays on Political Thought and History University of Chicago Press 1989

Posner Richard Antitrust Law Second Edition University of Chicago Press 2001

Postman Neil Amusing Ourselves to Death: Public Discourse in the Age of Show Business. USA: Penguin 1985

Sahlins, Marshall Social Stratification in Polynesia. Monographs of the American Ethnological Society, 29. Seattle: University of Washington Press 1958 Sauter, Molly May 24, 2017 Persuasion and the other thing: A critique of big data methodologies in politics in ETHNOGRAPHY MATTERS, Facebook 
Starr, Kevin 1994 Americans and the California Dream: 1850-1915 Oxford University Press Susskind, David A World Without Work, Technology, Automation and How We Should Respond Penguin 2020

Varoufakis, Yanis. Another Now: Dispatches from an Alternative Present. London: The Bodley Head, 2020. p.144

Vertesi, Janet July, 2016 'What robots in space teach us about teamwork: A deep dive into NASA'

Wells HG Men Like Gods Cassell 1923

Wells, H.G. A Modern Utopia. New York, New York:

Penguin Group, 2005

Wells H G 1895 The Time Machine Heinemann

West, Geoffrey Scale, 2017 The Universal laws of Life, Growth, and Death in Organisms, Cities and Companies, Penguin

Wood, Gaby Living Dolls, 2002 A Magical History of the Quest for Mechanical Life, Faber and Faber

\section{Internet and Film Sources}

Bezos interview 23.07.2000

https:/www.youtube.comwatchv=MvuJCeV3KOo

Cleave, Peter Memory, body and dance, a review of literature www.tekaharoa.com Jan 192015

Cleave, Peter Books and Books 31 21.5.20 Campus Press Youtube https://www.facebook.com/1487263281501261/v ideos/266721651148057

Ex Machina 2014 Universal Pictures 
Venture City Amazon's Robotic Empire: Jeff Bezos' Smart Warehouses Nov 12020 Youtube George W Bush Provincial Center Forum and Leadership

https://www.youtube.com/watch?v=xu6vFIKAUxk Youtube April 272018

Bezos talks with his brother Nov 152017 https://www.youtube.com/watch?v=Hq89wYzOjfs Venture City Amazon's City of the Future Nov 7 2019 Youtube

Tirole Jean https://www.tsefr.eu/sites/default/files/TSE/images/conference/ Digital_conf_2020/tirole_digital_dystopia_080120.p $\underline{\mathrm{df}}$

2017 on Youtube Professor Andrew Ng https://www.youtube.com/watch?v=VasJplgi3z8 https://www.usatoday.com/story/money/2020/0 9/06/the-worlds-most- important-event-everyyear-since-1920/113604790/

Amazon Sidewalk Terrifies Us - YouTube TWIT This Week in Tech Sep 30 2020https://www.youtube.com/watch?v=VasJplgi $\underline{3 z 8}$

The Rise of The Machines More than 100,000 Robots at Amazon Warehouse - YouTube New York Times Sep 72018 David Streitfeld Amazon's Antitrust Antagonist Has a Breakthrough Idea; with a single, scholarly article, Lina Khan 29, has reframed decades of monopoly law 
Black Mirror Episode One Season Two Fifteen Million Merits

Globuchar, Amy (Senator) in the Congressional Hearings on Big Technology 17.11.20

Hunt, Rhian TMF Analyst: Amazon is Undervalued, Will Soar 40\% Higher Oct 12020

Review of Brave New World https:// nanopdf.com/download/brave-new-world5aed15e520f3c_pdf Mikaere, Buddy 'It turns our tupuna into cardboard caricatures': Buddy Mikaere reviews Anne Salmond $2017^{\circ}$

https://thespinoff.co.nz/books/22-11-2017/itturns-our-tipuna-into-cardboard-caricaturesbuddy-mikaere-reviews-anne-salmond/ RT EU launches antitrust probe of Amazon Nov 11 2020

https://www.youtube.com/watch?v=F4DaYSCIa2 $\mathrm{M}$

Venture City Amazon's City of the Future Nov 7 2019 Youtube

Ex Machina movie, Universal Pictures 2014

Galloway, Scott Dec 222017 Its time: break up Big Tech

https://www.youtube.com/watch?v=1ebKI4x_k8A Giridharadas (2019) Winners Take All Video RSA Minimate

Godfrey, Neil puts it in the title of his paper of 202102-23, 
'Techno-Feudalism - We are working for Big Tech for free'

https://vridar.org/2021/02/23/techno-feudalismwe-are-working-for-big-tech-for-free/

Hirst K.Kris December 132018 'Feudalism - A Political System of Medieval Europe and Elsewhere' https://www.thoughtco.com/feudalism-politicalsystem-of-medieval-europe-170918

Sackur, Stephen interview with Lina Khan on the BBC.

Venuto Damien Is Kris Faafoi being cowardly or clever on Google, Facebook?

21.03.20 New Zealand Herald Premium

Radio New Zealand 16.04.21, A deal to boost the local economy has been struck between the government and the global giant Amazon.

Maital, Shlomo Jeff Bezos Follows the Money https://timnovate.com/tag/bain/

$\mathrm{Ng}$, Andrew 2017 Artificial Intelligence is the new electricity

https: / / www.youtube.com/watch?v=21EiKfQYZXc

Peach, Sam of BBC Radio Documentaries of March 20, 2021,

Tricia Wang: The human insights missing from big data TED Talk 